\title{
Albumin-bound paclitaxel in solid tumors: clinical development and future directions
}

This article was published in the following Dove Press journal:

Drug Design, Development and Therapy

24 July 2015

Number of times this article has been viewed

\section{Madappa N Kundranda' Jiaxin $\mathrm{Niu}^{2}$}

'Medical Oncology, Banner MD Anderson Cancer Center, Gilbert, ${ }^{2}$ Department of Medical Oncology, Cancer Treatment Centers of America, Goodyear, AZ, USA
Correspondence: Madappa N Kundranda Banner MD Anderson Cancer Center, Medical Oncology, 2940 Suite 450, E Banner Gateway Dr, Gilbert, AZ 85234, USA

Tel +l 4802563623

Fax +I 4802564003

Email madappa.kundranda@bannerhealth. com

\begin{abstract}
Albumin-bound paclitaxel (nab-paclitaxel) is a solvent-free formulation of paclitaxel that was initially developed more than a decade ago to overcome toxicities associated with the solvents used in the formulation of standard paclitaxel and to potentially improve efficacy. Nab-paclitaxel has demonstrated an advantage over solvent-based paclitaxel by being able to deliver a higher dose of paclitaxel to tumors and decrease the incidence of serious toxicities, including severe allergic reactions. To date, nab-paclitaxel has been indicated for the treatment of three solid tumors in the USA. It was first approved for the treatment of metastatic breast cancer in 2005, followed by locally advanced or metastatic non-small-cell lung cancer in 2012, and most recently for metastatic pancreatic cancer in 2013. Nab-paclitaxel is also under investigation for the treatment of a number of other solid tumors. This review highlights key clinical efficacy and safety outcomes of nab-paclitaxel in the solid tumors for which it is currently indicated, discusses ongoing trials that may provide new data for the expansion of $n a b$-paclitaxel's indications into other solid tumors, and provides a clinical perspective on the use of $n a b$-paclitaxel in practice.
\end{abstract}

Keywords: $n a b$-paclitaxel, breast, lung, pancreas, ovarian, melanoma

\section{Nab-paclitaxel development}

Paclitaxel is widely used for the treatment of solid tumors ${ }^{1-3}$ however, the solvent used in the commercial formulation of solvent-based ( $\mathrm{sb}$ )-paclitaxel, polyoxyethylated castor oil (Kolliphor ${ }^{\circledR}$ EL, formerly known as Cremophor EL; BASF SE, Ludwigshafen, Germany), is associated with severe, sometimes fatal hypersensitivity reactions. ${ }^{4-6}$ To reduce the risk of hypersensitivity reactions with sb-paclitaxel, patients are routinely pretreated with corticosteroids and antihistamines. ${ }^{1,2}$ Furthermore, some studies have shown that Kolliphor EL can entrap paclitaxel in solvent micelles, making the drug less available to enter tumors, thereby limiting its clinical efficacy. ${ }^{6-8}$

$N a b$-paclitaxel is a solvent-free albumin-bound form of paclitaxel. ${ }^{2,3,9}$ Compared with sb-paclitaxel, nab-paclitaxel has several advantages, including the ability to deliver significantly higher doses of paclitaxel over a shorter infusion time (30 minutes vs 3 hours for sb-paclitaxel) and the elimination of the need for pre-medications to prevent hypersensitivity reactions. Other advantages of $n a b$-paclitaxel over sb-paclitaxel include enhanced transport of paclitaxel across endothelial cells and greater delivery of paclitaxel to tumors. ${ }^{9}$ Because $n a b$-paclitaxel is formulated with albumin, it is postulated that the drug uses endogenous albumin transport pathways, including receptormediated transcytosis, to cross endothelial cell monolayers and enter tumors. ${ }^{9,10}$ In a preclinical study, fourfold more nab-paclitaxel was transported across endothelial cells than sb-paclitaxel. ${ }^{9}$ Moreover, it was found that Kolliphor EL inhibited the binding of paclitaxel to albumin and endothelial cells, potentially limiting intratumoral 
uptake of paclitaxel. ${ }^{9}$ Albumin, or albumin-bound molecules such as nab-paclitaxel, may also find a way into the tumor microenvironment via the enhanced permeation and retention effect, which proposes that molecules are able to escape the circulation through gaps between endothelial cells resulting from leaky vasculature around tumors. ${ }^{11}$ A comprehensive review of $n a b$-paclitaxel's mechanism of action and delivery system has recently been published. ${ }^{12}$

Recent studies on the population pharmacokinetics (PK) and pharmacodynamics (PD) of nab-paclitaxel demonstrated that pharmacologic features of nab-paclitaxel appear to be distinct from those of sb-paclitaxel. ${ }^{13,14}$ These distinct features likely contribute to the differences in clinical safety and efficacy between the two paclitaxel formulations. ${ }^{13}$ Specifically, compared with sb-paclitaxel, nab-paclitaxel was associated with faster and deeper tissue penetration and slower elimination of paclitaxel. Tissue distribution of paclitaxel was found to be dependent on the drug carrier complex. ${ }^{14}$ These results confirm preclinical findings that more paclitaxel may be able to enter the tumor when delivered as nab-paclitaxel ${ }^{9}-$ and with more rapid distribution to tissues, the duration of high systemic exposure is shorter. This may, in turn, explain the observation of the lower frequency of some severe adverse events, such as neutropenia, with nab-paclitaxel than with sb-paclitaxel, despite that nab-paclitaxel demonstrates a higher paclitaxel dose intensity (26\%-49\% higher) than sb-paclitaxel. ${ }^{15-17}$ Furthermore, in the population PK/PD study, a threshold plasma concentration for $n a b$-paclitaxel was defined at $0.84 \mathrm{mM}$, such that the duration of time spent above this concentration predicted the probability of neutropenia. ${ }^{13}$ Compared with that previously reported for sb-paclitaxel $(0.05 \mathrm{mM})$, the threshold plasma paclitaxel concentration was nearly 17 -fold higher for nab-paclitaxel. ${ }^{13}$ Consistent with these findings, in trials to establish the maximum tolerated dose (MTD) of nab-paclitaxel, it was found that the albumin-bound formulation of paclitaxel allowed for a higher dose delivery of paclitaxel compared with sb-paclitaxel. The MTD of $n a b$-paclitaxel was $71 \%$ to $88 \%$ higher than that reported for sb-paclitaxel for both the every3-weeks (q3w) regimen (300 vs $175 \mathrm{mg} / \mathrm{m}^{2}$ ) and the weekly regimen $\left(150 \mathrm{vs} 80 \mathrm{mg} / \mathrm{m}^{2}\right)$ in patients with advanced or metastatic solid tumors. ${ }^{18-20}$ Dose-limiting toxicities in these trials included neutropenia, peripheral neuropathy, stomatitis, and superficial keratopathy. ${ }^{18-20}$ With respect to peripheral neuropathy, a common taxane-associated side effect, the incidence of peripheral neuropathy with $n a b$-paclitaxel compared to with sb-paclitaxel has varied across trials. ${ }^{15,16}$ Differences in patient populations, dosing schedules, and adverse-event management strategies may have played a role in the varying incidence rates. Nevertheless, the ability to deliver a higher dose of paclitaxel and the enhanced tissue distribution and tumor uptake of nab-paclitaxel versus sb-paclitaxel likely contribute to the more favorable efficacy and safety profile of the albumin-bound formulation of paclitaxel.

\section{Nab-paclitaxel in breast cancer, non- small-cell lung cancer (NSCLC), and pancreatic cancer}

\section{Breast cancer}

A Phase I dose-escalation trial of 19 patients with advanced solid tumors established the MTD of nab-paclitaxel at $300 \mathrm{mg} / \mathrm{m}^{2}$ given $\mathrm{q} 3 \mathrm{w} .{ }^{18}$ Dose-limiting toxicities included peripheral neuropathy, stomatitis, and superficial keratopathy, which occurred at a dose of $375 \mathrm{mg} / \mathrm{m}^{2}$. There were no reported hypersensitivity reactions despite the absence of steroid premedication and a short infusion time (30 minutes). The MTD and schedule were subsequently evaluated in a Phase II trial for the first- or $\geq$ second-line treatment of patients with metastatic breast cancer (MBC). The trial reported an overall response rate (ORR) of $48 \%$ for the intent-to-treat population of patients, with a $64 \%$ ORR in chemotherapy-naïve patients. ${ }^{21}$ Time to tumor progression was 6.1 months and median overall survival (OS) was 14.6 months. These results supported the study of nab-paclitaxel vs sb-paclitaxel in a Phase III trial of patients with MBC. ${ }^{15}$ In this study, the dose of $n a b$-paclitaxel was reduced to $260 \mathrm{mg} / \mathrm{m}^{2} \mathrm{q} 3 \mathrm{w}$ to lower the risk for severe toxicities, but the dose intensity was still $49 \%$ higher than that of sb-paclitaxel, which was dosed at 175 $\mathrm{mg} / \mathrm{m}^{2}$ q3w. ${ }^{15} \mathrm{Nab}$-paclitaxel demonstrated a significantly higher ORR (33\% vs 19\%; $P=0.001$; primary endpoint) and significantly longer time to tumor progression (5.3 vs 3.9 months; $P=0.006$ ) compared with sb-paclitaxel (Table 1). OS was not significantly different between the two paclitaxel treatments for the overall population (14.9 vs 12.8 months; $P=0.374$ ), but patients who received $n a b$-paclitaxel as secondline or greater did have a significantly longer OS than those who received sb-paclitaxel (13.0 vs 10.7 months; hazard ratio [HR] $0.73 ; P=0.024)$. Grade 4 neutropenia was more common with sb-paclitaxel than with nab-paclitaxel $(22 \%$ vs $9 \%$ ), but the incidence of grade 3 sensory neuropathy was higher with nab-paclitaxel than with sb-paclitaxel (10\% vs $2 \%$ ) (Table 1). Sensory neuropathy was managed with dose interruptions or reductions and improved to grade 2 or less in a median of 22 days.

Based on these positive results, nab-paclitaxel received its first US Food and Drug Administration (FDA) approval 


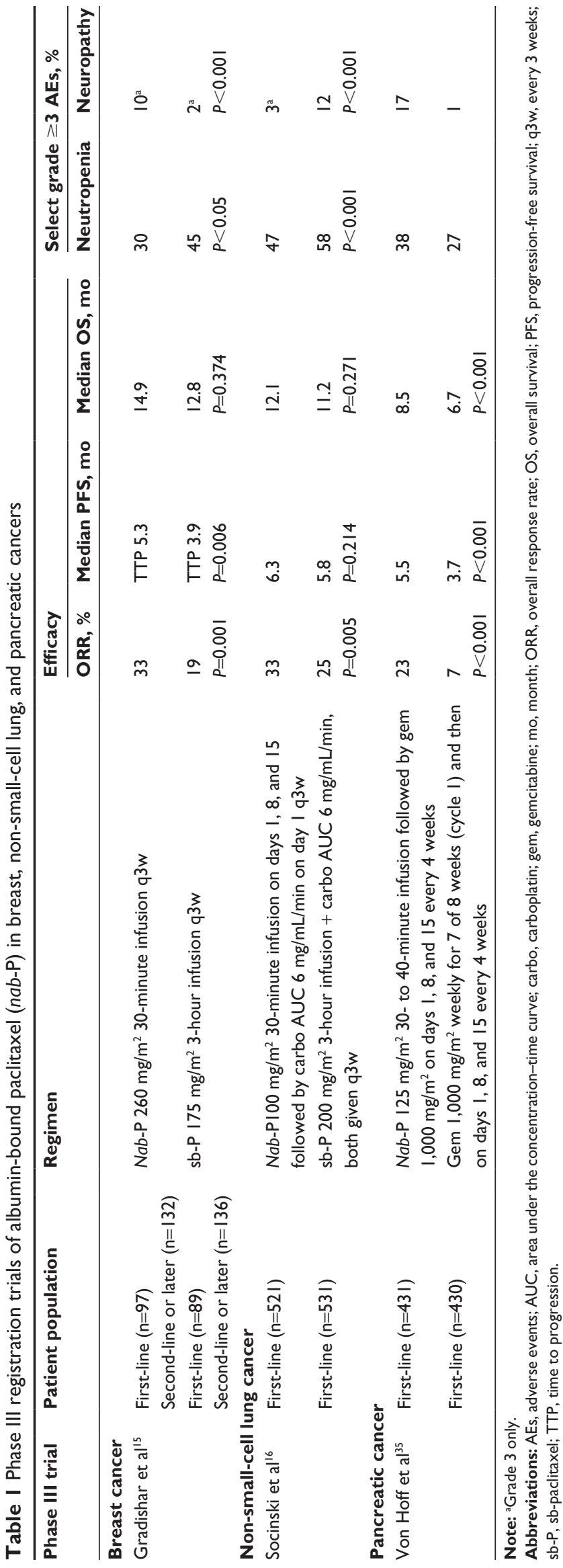

in 2005 for the treatment of MBC. Nab-paclitaxel is indicated for patients with breast cancer after failure of combination chemotherapy for metastatic disease or relapse within 6 months of adjuvant chemotherapy. ${ }^{3}$ Prior therapy should have included an anthracycline unless clinically contraindicated.

\section{NSCLC}

A Phase II dose-finding study found that $100 \mathrm{mg} / \mathrm{m}^{2}$ weekly $n a b$-paclitaxel combined with $\mathrm{q} 3 \mathrm{w}$ carboplatin area under the concentration-time curve (AUC) 6 provided the best clinical benefit-risk ratio compared with several other doses/ schedules of nab-paclitaxel plus carboplatin in patients with advanced NSCLC. ${ }^{22}$ This dose/schedule showed comparable efficacy to the other dosing cohorts and had the least severe adverse events. These results led to a larger Phase III trial of more than 1,000 patients with advanced NSCLC in which the mentioned dose/schedule of nab-paclitaxel plus carboplatin was compared with $200 \mathrm{mg} / \mathrm{m}^{2}$ sb-paclitaxel plus carboplatin AUC $6 \mathrm{q} 3 \mathrm{w} .{ }^{16}$ The study met its primary endpoint with improvement in ORR for $n a b$-paclitaxel plus carboplatin versus sb-paclitaxel plus carboplatin (33\% vs $25 \% ; P=0.005$; Table 1). However, there was no statistically significant difference in median progression-free survival (PFS) (6.3 vs 5.8 months) or median OS (12.1 vs 11.2 months) for $n a b$-paclitaxel plus carboplatin versus sb-paclitaxel plus carboplatin (Table 1). A subset analysis of the Phase III trial based on predefined stratification factors revealed that patients with squamous histology treated with nab-paclitaxel plus carboplatin had a significantly higher ORR compared with those who received sb-paclitaxel plus carboplatin ( $41 \%$ vs $24 \% ; P<0.001)$. In addition, the median OS was significantly longer in patients $\geq 70$ years of age who were treated with nab-paclitaxel plus carboplatin compared with sb-paclitaxel plus carboplatin (19.9 vs 10.4 months; $P=0.009$ ). In the overall treated population, grade $\geq 3$ neutropenia ( $47 \%$ vs $58 \%$ ) and sensory neuropathy ( $3 \%$ vs $12 \%)$ occurred significantly less frequently with $n a b$-paclitaxel plus carboplatin $(P<0.001$; Table 1), while grade $\geq 3$ thrombocytopenia ( $18 \%$ vs $9 \%$ ) and anemia $(27 \%$ vs 7\%) were more common with nab-paclitaxel plus carboplatin than with sb-paclitaxel plus carboplatin $(P<0.001)$. The safety profiles were similar, regardless of patient age or histology. ${ }^{23,24}$ Based on the findings of this Phase III trial, the FDA-approved $n a b$-paclitaxel in combination with carboplatin for the first-line treatment of patients with locally advanced or metastatic NSCLC who are not candidates for curative surgery or radiation. ${ }^{3}$ 


\section{Pancreatic cancer}

Gemcitabine monotherapy is one of the most widely used agents in the treatment of metastatic pancreatic cancer, based on a seminal study by Burris et al that demonstrated a median survival of $\approx 6$ months. ${ }^{25} \mathrm{~A}$ decade later and after numerous failed clinical trials, erlotinib in combination with gemcitabine was FDA approved for the treatment of locally advanced, unresectable, or metastatic pancreatic cancer, ${ }^{26}$ partly based on a statistically significant 0.3 -month survival advantage for erlotinib plus gemcitabine vs gemcitabine alone. ${ }^{27}$ However, in routine clinical practice, this combination is very selectively used in a small subset of patients. Several other Phase III trials of gemcitabine doublets failed to demonstrate a significant survival advantage over gemcitabine alone..$^{25,27-32}$

$N a b$-paclitaxel was selected as a combination partner for gemcitabine because it has been shown to synergize with gemcitabine and was associated with increased intratumoral delivery of gemcitabine and stromal depletion. ${ }^{33} \mathrm{In}$ a Phase I/II trial, the MTD of $n a b$-paclitaxel in combination with $1,000 \mathrm{mg} / \mathrm{m}^{2}$ gemcitabine was established at $125 \mathrm{mg} / \mathrm{m}^{2}$; both agents were given weekly for the first 3 of 4 weeks (qw 3/4) in patients with advanced pancreatic cancer. ${ }^{33,34}$ For patients treated at the MTD ( $n=44)$, the ORR was $48 \%$ and median OS was 12.2 months. This led to a large multinational Phase III trial of more than 850 patients in who $125 \mathrm{mg} / \mathrm{m}^{2}$ nab-paclitaxel plus $1,000 \mathrm{mg} / \mathrm{m}^{2}$ gemcitabine qw $3 / 4$ was compared with $1,000 \mathrm{mg} / \mathrm{m}^{2}$ gemcitabine alone (given weekly for 7 of 8 weeks during cycle 1 and then qw $3 / 4$ for cycle 2 and beyond) (Table 1$) \cdot{ }^{35}$ Median OS (primary endpoint) was significantly longer with $n a b$-paclitaxel plus gemcitabine versus gemcitabine alone ( 8.5 vs 6.7 months; $P<0.001)$. The treatment benefit of $n a b$-paclitaxel plus gemcitabine over gemcitabine alone was consistent across most prespecified subgroups, including those patients with more advanced disease (eg, poorer performance status, liver metastasis, $\geq 3$ sites of metastatic disease, and carbohydrate antigen 19-9 levels $59 \times$ the upper limit of normal). ${ }^{35}$ Grade $\geq 3$ neutropenia ( $38 \%$ vs $27 \%$ ), fatigue ( $17 \%$ vs $7 \%$ ), and neuropathy ( $17 \%$ vs $1 \%$ ) were higher with $n a b$-paclitaxel plus gemcitabine versus gemcitabine alone; no patients experienced grade 4 neuropathy in either arm. As observed in other trials, ${ }^{15,16,36}$ the grade 3 neuropathy associated with nabpaclitaxel resolved for a majority of patients and improved to grade 1 or lower in a median of 29 days.

Nab-paclitaxel plus gemcitabine was the first gemcitabine doublet to demonstrate a clinically meaningful benefit over gemcitabine alone in a Phase III trial of advanced/metastatic pancreatic cancer. ${ }^{25,27-32}$ In 2013, nab-paclitaxel plus gemcitabine became an FDA-approved regimen for the first-line treatment of patients with metastatic pancreatic cancer. ${ }^{3}$

Based on the hypothesis of secreted protein acidic and rich in cysteine (SPARC), an albumin-binding protein, playing a role in the delivery of $n a b$-paclitaxel to tumors, analyses have been performed to examine the relationship between SPARC expression and outcome in patients treated with $n a b$-paclitaxel plus gemcitabine. In the Phase I/II trial, high versus low stromal SPARC expression was associated with longer OS in the nab-paclitaxel plus gemcitabine arm (17.8 vs 8.1 months; $P=0.0431$ ), suggesting that SPARC may be a biomarker for pancreatic cancer that facilitates accumulation of nab-paclitaxel into tumors. ${ }^{33}$ An analysis of SPARC status in the Phase III Metastatic Pancreatic Adenocarcinoma Clinical Trial found that stromal, tumor, and plasma SPARC were not prognostic for survival or predictive of survival in either treatment arm. ${ }^{37}$

\section{Clinical perspectives and future directions \\ Breast cancer}

Since its approval in 2005, nab-paclitaxel has been studied in a variety of breast cancer patient populations and with varying doses and schedules. ${ }^{36,38}$ It has demonstrated efficacy in patients with poor prognostic factors and aggressive disease features,${ }^{39}$ including those with triple-negative breast cancer (TNBC) ${ }^{40,41}$ Although the approved dose of nab-paclitaxel for the treatment of MBC is $260 \mathrm{mg} / \mathrm{m}^{2} \mathrm{q} 3 \mathrm{w}$, determining the optimal dose and schedule when it is used as a single agent or in combination with other agents is an ongoing effort and a source of widely varying trial outcomes. In a preliminary analysis of the Cancer and Leukemia Group B (CALGB 40502) Phase III trial, which evaluated three combination regimens for the treatment of patients with human epidermal growth factor receptor 2 (HER2)-negative MBC (nabpaclitaxel $150 \mathrm{mg} / \mathrm{m}^{2}$ qw $3 / 4$ plus bevacizumab $10 \mathrm{mg} / \mathrm{kg}$ every 2 weeks [q2w] or sb-paclitaxel $90 \mathrm{mg} / \mathrm{m}^{2}$ qw 3/4 plus bevacizumab $10 \mathrm{mg} / \mathrm{kg}$ q2 $\mathrm{w}$ or ixabepilone $16 \mathrm{mg} / \mathrm{kg}$ qw $3 / 4$ plus bevacizumab $10 \mathrm{mg} / \mathrm{kg} \mathrm{q} 2 \mathrm{w}$ ), similar PFS (primary endpoint) was found for the $n a b$-paclitaxel and sb-paclitaxel arms (9.2 vs 10.6 months; HR 1.19; 95\% confidence interval, $0.96-1.49 ; P=0.12) .{ }^{42}$ However, high rates of hematologic and non-hematologic toxicity, including peripheral neuropathy, in the nab-paclitaxel plus bevacizumab arm suggest that the $150 \mathrm{mg} / \mathrm{m}^{2}$ weekly schedule of $n a b$-paclitaxel in combination with bevacizumab may not have been optimal. Early discontinuations and dose reductions due to these toxicities in the 
nab-paclitaxel arm may have led to insufficient dose intensity and duration of therapy. With bevacizumab's approval being revoked by the FDA in MBC, the more pertinent clinical question is whether weekly $n a b$-paclitaxel is superior to weekly paclitaxel in the absence of bevacizumab. A head-to-head clinical trial would help to answer this question.

A recent large Phase III trial of 1,204 patients did demonstrate superiority of $150 \mathrm{mg} / \mathrm{m}^{2} n a b$-paclitaxel given weekly ( $\mathrm{n}=606$ ) over $80 \mathrm{mg} / \mathrm{m}^{2} \mathrm{sb}$-paclitaxel given weekly ( $n=598$ ), both followed by epirubicin and cyclophosphamide, as neoadjuvant chemotherapy in patients with early breast cancer; pathological complete response ( $\mathrm{pCR}$ ) rates were $38 \%$ and $29 \%$, respectively (odds ratio $1.53 ; P=0.001$ ). ${ }^{43}$ Patients with TNBC appeared to derive the greatest benefit from $n a b$-paclitaxel therapy (odds ratio 2.69; $P<0.001$ ). The incidence of grade $\geq 3$ neutropenia was high with both treatments, $61 \%$ and $62 \%$, respectively $(P=0.636)$, whereas the incidence of grade $\geq 3$ peripheral neuropathy was significantly higher with nab-paclitaxel (10\%) versus sb-paclitaxel treatment $(3 \% ; P<0.001)$. Of note, after 400 patients were treated in the $n a b$-paclitaxel arm, the dose of $n a b$-paclitaxel was reduced to $125 \mathrm{mg} / \mathrm{m}^{2}$. Long-term follow-up of this trial will determine if the increased $\mathrm{pCR}$ rates translate into improved disease-free survival and OS.

A Phase II trial of 302 patients with MBC treated in the first-line demonstrated that $n a b$-paclitaxel dosed at $150 \mathrm{mg} / \mathrm{m}^{2}$ qw 3/4 had a better efficacy and safety profile compared with another sb taxane, docetaxel, given at $100 \mathrm{mg} / \mathrm{m}^{2} \mathrm{q} 3 \mathrm{w} .{ }^{38}$ The $150 \mathrm{mg} / \mathrm{m}^{2}$ weekly dose showed significant improvement in PFS compared with docetaxel (median 12.9 vs 7.5 months; $P=0.0065$ ) and demonstrated the longest median OS (33.8 months) compared with the other $n a b$-paclitaxel regimens (22.2 months for $100 \mathrm{mg} / \mathrm{m}^{2}$ weekly and 27.7 months for $300 \mathrm{mg} / \mathrm{m}^{2} \mathrm{q} 3 \mathrm{w}$ ) and docetaxel (26.6 months). ${ }^{36,38}$ The $150 \mathrm{mg} / \mathrm{m}^{2}$ dose was associated with more dose reductions and a higher incidence of grade 3 neuropathy than docetaxel ( $22 \%$ vs $12 \%$ ); however, sensory neuropathy associated with $n a b$-paclitaxel improved from grade 3 to grade 2 or lower in half the amount of time versus that associated with docetaxel (a median of 20 vs 41 days).

While these clinical trial results are interesting, it is not entirely clear how relevant these doses/schedules are to clinical use. According to a recent US claims study analyzing 664 eligible records of patients with $\mathrm{MBC}$, a weekly schedule of nab-paclitaxel was dispensed more often than the $\mathrm{q} 3 \mathrm{w}$ schedule (71\% vs 29\%) from January 2005 to September $2012 .{ }^{44}$ Thus, it appears that the weekly dose of $n a b$-paclitaxel has been widely adapted into clinical practice for the treatment of MBC. The recommended doses and schedules of singleagent $n a b$-paclitaxel by the National Comprehensive Cancer Network (NCCN) for the systemic treatment of recurrent or $\mathrm{MBC}$ are $260 \mathrm{mg} / \mathrm{m}^{2} \mathrm{q} 3 \mathrm{w}$ and 100 or $150 \mathrm{mg} / \mathrm{m}^{2} \mathrm{qw} 3 / 4 .{ }^{45}$ Currently, the NCCN does not recommend a $n a b$ paclitaxel-based combination regimen for the treatment of any type of breast cancer.

Very few treatment options exist for patients with TNBC, an aggressive disease that accounts for about $20 \%$ to $25 \%$ of all breast cancer. ${ }^{46}$ Patients with metastatic TNBC tend to be resistant to single-agent chemotherapy and often require combination chemotherapy. ${ }^{45}$ Independent trials have demonstrated activity of nab-paclitaxel in combination with carboplatin, gemcitabine, or bevacizumab for the treatment of metastatic TNBC. ${ }^{41,42,47}$ The Phase II/III Triple-Negative Albumin-Bound Paclitaxel Combination International Treatment Study (tnAcity; NCT01881230) will evaluate the efficacy and safety of $n a b$-paclitaxel plus gemcitabine (or carboplatin) versus gemcitabine plus carboplatin as firstline treatment of patients with TNBC (Table 2). ${ }^{48}$ During the Phase II portion of the trial, the best combination partner for $n a b$-paclitaxel will be determined (gemcitabine or carboplatin) and carried forward into the Phase III trial where the selected $n a b$-paclitaxel regimen will be compared with gemcitabine plus carboplatin. Planned enrollment for this trial is 790 patients and the primary endpoint is PFS. There are a number of other ongoing Phase III/IV trials evaluating the safety and efficacy of nab-paclitaxel in various breast cancer settings, and these are listed in Table $2 .{ }^{49-54}$

\section{NSCLC}

In the USA, $>70 \%$ of patients with lung cancer are 65 years of age or older and the median age of diagnosis is 70 years..$^{55}$ Historically, elderly patients have been underrepresented in Phase III trials of advanced NSCLC (15\% to $28 \%$ of enrolled patients were $\geq 70$ years of age), ${ }^{23,56-60}$ thus application of these trial results to the elderly population has limitations. Other challenges in treating elderly patients include comorbidities and altered PK of drugs with age. ${ }^{61,62}$ As a result, patients above age 70 years with lung cancer tend to be undertreated due to lack of sufficient evidence. In a subset analysis of the Phase III NSCLC trial, it was found that elderly patients who were treated with nab-paclitaxel plus carboplatin had a nearly 10-month improvement in OS compared with patients treated with sb-paclitaxel plus carboplatin $(P=0.009) .{ }^{16}$ The safety profile of $n a b$-paclitaxel plus carboplatin in the elderly population was similar to the overall trial population. ${ }^{23}$ Based on this positive result, one 


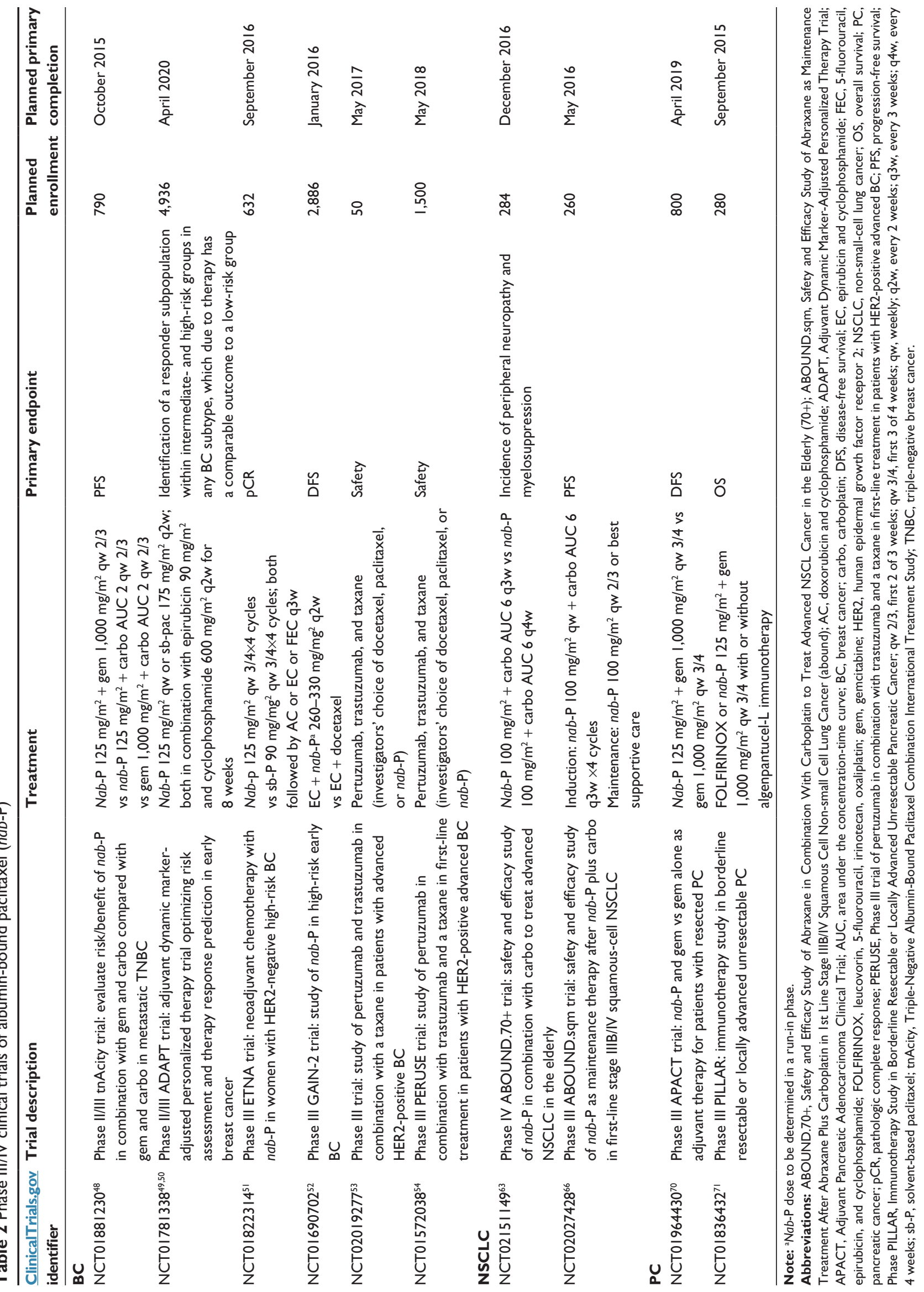


of the Albumin-Bound Paclitaxel in NSCLC (ABOUND) Phase III trials, ABOUND.70+ (NCT02151149), will evaluate the efficacy and safety of $n a b$-paclitaxel plus carboplatin in elderly patients (aged $\geq 70$ years) with advanced NSCLC (Table 2). ${ }^{63}$ Patients will be randomly assigned to either $100 \mathrm{mg} / \mathrm{m}^{2}$ weekly $n a b$-paclitaxel given on day 1,8 , and 15 plus carboplatin AUC 6 given on day 1 every 21 days or the same regimen with 1 week off for a 28-day cycle. Planned enrollment is 284 patients. The primary endpoint is safety (incidence of peripheral neuropathy or myelosuppression).

Squamous NSCLC portends a poorer prognosis compared with other non-squamous subtypes, with 1- and 5-year survival rates of $14.6 \%$ and $1.6 \%$, respectively. ${ }^{64}$ Treatment options for patients with squamous NSCLC are also limited. ${ }^{65}$ Pemetrexed and bevacizumab are not indicated for these patients, and the known mutations targetable by currently approved agents are rare in squamous NSCLC. ${ }^{65}$ Current NCCN guidelines recommend platinum-based doublets as a category 1 option, and cisplatin plus vinorelbine in combination with cetuximab as a category $2 \mathrm{~B}$ recommendation in patients with squamous NSCLC. ${ }^{65}$ In the Phase III NSCLC trial of nab-paclitaxel plus carboplatin versus sbpaclitaxel plus carboplatin, patients with squamous histology treated with nab-paclitaxel plus carboplatin achieved an ORR that was nearly double that of patients treated with sb-paclitaxel plus carboplatin $(P<0.001) .{ }^{16}$ The safety profile of $n a b$-paclitaxel plus carboplatin in patients with squamous histology was similar to the overall treated population of patients. ${ }^{16}$ This intriguing outcome provided the rationale for the Phase III ABOUND squamous maintenance trial (ABOUND.sqm; NCT02027428) that will evaluate the safety and efficacy of $n a b$-paclitaxel as maintenance therapy after first-line treatment with $n a b$-paclitaxel plus carboplatin in patients with stage IIIB/IV squamous-cell NSCLC (Table 2) ${ }^{66}$ After induction, patients will receive maintenance therapy of either $n a b$-paclitaxel plus best supportive care or best supportive care alone. Planned enrollment is 260 patients and the primary endpoint is PFS.

\section{Pancreatic cancer}

There are limited options for adjuvant therapy for pancreatic cancer and no adjuvant regimen has received regulatory approval in the USA. The NCCN guidelines recommend 5-fluorouracil (5-FU) plus leucovorin or gemcitabine as adjuvant chemotherapy options, but for chemotherapy alone, gemcitabine is preferred over 5-FU/leucovorin based on its more favorable safety profile. ${ }^{67}$ Because a majority of patients receiving adjuvant gemcitabine relapse with recurrence rates in the range of $77 \%$ to $81 \%$ in Phase III trials, better treatment options are needed. ${ }^{68,69}$ The regimen used in the Phase III MPACT trial of nab-paclitaxel plus gemcitabine versus gemcitabine is now being evaluated in the Phase III Adjuvant Pancreatic Adenocarcinoma Clinical Trial (APACT; NCT01964430) as adjuvant therapy for patients with resected pancreatic cancer (Table 2). ${ }^{70}$ Patients will be randomly assigned to receive 125 $\mathrm{mg} / \mathrm{m}^{2}$ nab-paclitaxel plus gemcitabine $1,000 \mathrm{mg} / \mathrm{m}^{2}$ given on days 1,8 , and 15 of a 28-day cycle for a total of six cycles or gemcitabine alone. Planned enrollment is 800 patients and the primary endpoint is disease-free survival.

Based on the positive results of the Phase III MPACT study, there has been a significant increase in the use of $n a b$-paclitaxel plus gemcitabine as a backbone regimen, and several studies are evaluating this combination with other novel therapies, including immunotherapy as in the Phase III Immunotherapy Study in Borderline Resectable or Locally Advanced Unresectable Pancreatic Cancer (PILLAR) trial (Table 2). ${ }^{71}$ As we move forward with this backbone regimen, future studies will likely address whether the qw 3/4 schedule, currently the FDA-approved schedule for $\mathrm{MPC},{ }^{3}$ will be optimal for regimens of $n a b$-paclitaxel as a combination partner or as part of a novel sequence of regimens.

\section{Clinical benefit of nab-paclitaxel in other solid tumors}

While $n a b$-paclitaxel is currently only indicated by the FDA in three solid tumors, it is routinely used in the USA for the treatment of other solid tumors based on recommendations from the NCCN. At this time, melanoma and ovarian cancer (including fallopian tube cancer and primary peritoneal cancer) are the only solid tumors outside of the current indications in which nab-paclitaxel is an NCCN-recommended treatment option. ${ }^{72,73}$ According to the NCCN guidelines, $n a b$-paclitaxel is listed as a category $2 \mathrm{~A}$ recommendation for the treatment of advanced or metastatic melanoma, based on positive Phase II trial data in which nab-paclitaxel led to response rates of $22 \%$ to $26 \%$ in chemotherapy-naïve patients with metastatic melanoma. ${ }^{74,75}$ Response rates have historically been $<20 \%$ with commonly used cytotoxics including dacarbazine, temozolomide, and sb-paclitaxel with or without carboplatin. ${ }^{72}$ In a head-to-head Phase III trial of $n a b$-paclitaxel $150 \mathrm{mg} / \mathrm{m}^{2}$ qw $3 / 4$ vs dacarbazine $1,000 \mathrm{mg} / \mathrm{m}^{2} \mathrm{q} 3 \mathrm{w}$ for the treatment of chemotherapy-naïve patients, $n a b$-paclitaxel led to a significant improvement in the primary endpoint of PFS (4.8 vs 2.5 months; HR 0.792; $P=0.044$ ) and a 2-month, nonsignificant improvement in OS (12.6 vs 10.5 months; HR 0.897; $P=0.271) .{ }^{76}$ Neuropathy 
was a common grade $\geq 3$ treatment-related event observed with $n a b$-paclitaxel ( $25 \%$ vs $0 \%$ for dacarbazine); however, these events improved by $\geq 1$ grade in a median of 28 days. Given the advent and success of immunomodulatory drugs in the treatment of melanoma, a number of Phase II trials evaluating combinations of $n a b$-paclitaxel with this class of drugs are underway in metastatic melanoma. ${ }^{77,78}$

$N a b$-paclitaxel also has a category $2 \mathrm{~A}$ recommendation for the treatment of recurrent ovarian cancer. ${ }^{73}$ The NCCN recommendation for retreatment of ovarian cancer with nabpaclitaxel is based on a Phase II trial that showed an ORR of $64 \%$ and median PFS of 8.5 months. ${ }^{79}$ Patients received $n a b$-paclitaxel dosed at $260 \mathrm{mg} / \mathrm{m}^{2} \mathrm{q} 3 \mathrm{w}$. Neutropenia (24\%) and neuropathy ( $9 \%$; no grade 4$)$ were the most common grade $\geq 3$ events. In patients with platinum-sensitive recurrent ovarian cancer, platinum-based therapy either as a single agent or in combination is widely accepted as first-line therapy. ${ }^{73}$ Although nab-paclitaxel has shown activity in this setting, it has not been studied in a Phase III trial of platinum-sensitive recurrent ovarian cancer to date. Unfortunately, almost all patients with platinum-sensitive ovarian cancer will develop resistance to platinum over time. ${ }^{80}$ Platinum-resistant ovarian cancer is generally treated with non-platinum-based chemotherapy; however response rates are low and prognosis is poor. At least two Phase II trials examined the safety and efficacy of nab-paclitaxel in this setting. In a Gynecologic Oncology Group study, 47 patients with both platinum-resistant and taxane-resistant ovarian cancer were treated with nab-paclitaxel, $100 \mathrm{mg} / \mathrm{m}^{2}$ days 1,8 , and 15 on a 28 -day schedule. ${ }^{81}$ The response rate was $23 \%$, and $36 \%$ of patients had stable disease. A second study investigated the combination of $n a b$-paclitaxel (using the same dosing schedule) plus bevacizumab (10 mg/kg given on days 1 and 15) in platinum-resistant patients. ${ }^{82}$ Of 48 patients enrolled, the ORR was $50 \%$ and $29 \%$ had stable disease. Taken together, these Phase II studies indicate potential activity of $n a b$-paclitaxel against platinum-resistant ovarian cancer. Further studies are needed in this population of patients with very limited options.

\section{Conclusion}

Given the success of $n a b$-paclitaxel in the treatment of MBC, advanced or metastatic NSCLC, and metastatic pancreatic cancer, the potential for $n a b$-paclitaxel to improve disease outcomes in settings with an unmet need should be evaluated. Several Phase III/IV studies in select populations of patients with breast cancer, NSCLC, and pancreatic cancer are currently under investigation and may lead to expanded indications of nab-paclitaxel in these disease areas (Table 2). In addition, a number of Phase II trials in other solid tumors, including urothelial, ${ }^{81}$ squamous-cell carcinoma of the head and neck, ${ }^{83}$ gastric cancer, ${ }^{84}$ and colorectal and small bowel carcinoma, ${ }^{85}$ are ongoing and should provide us with information regarding the role of $n a b$-paclitaxel in the treatment of these tumor types as well. Other encapsulated (ie, liposomes and polymers) forms of paclitaxel are in development. ${ }^{86}$ However, nab-paclitaxel is currently the only FDA- and European Medicines Agency-approved encapsulated form of paclitaxel. ${ }^{3,87}$ Differences in efficacy, safety, and PK/PD properties between these paclitaxel formulations remain to be determined in clinical trials.

\section{Acknowledgments}

Medical writing assistance was provided by Kerry R Garza, PhD, MediTech Media, Ltd, funded by Celgene.

\section{Disclosure}

MNK has received consulting fees for advisory board participation and for lectures from Celgene. JN has received consulting fees or honoraria for advisory board participation from Celgene.

\section{References}

1. Taxotere $^{\circledR}$ (docetaxel) injection concentrate, intravenous infusion (IV) [package insert]. Bridgewater, NJ: Sanofi-Aventis; 2013.

2. Taxol ${ }^{\mathbb{}}$ (paclitaxel) injection [package insert]. Princeton, NJ: BristolMyers Squibb; 2011.

3. Abraxane ${ }^{\circledR}$ for injectable suspension (paclitaxel protein-bound particles for injectable suspension) (albumin-bound). Summit, NJ: Celgene Corporation; 2014.

4. Gelderblom H, Verweij J, Nooter K, Sparreboom A. Cremophor EL: the drawbacks and advantages of vehicle selection for drug formulation. Eur J Cancer. 2001;37(13):1590-1598.

5. Weiss RB, Donehower RC, Wiernik PH, et al. Hypersensitivity reactions from taxol. J Clin Oncol. 1990;8(7):1263-1268.

6. ten Tije AJ, Verweij J, Loos WJ, Sparreboom A. Pharmacological effects of formulation vehicles: implications for cancer chemotherapy. Clin Pharmacokinet. 2003;42(7):665-685.

7. van Tellingen O, Huizing MT, Panday VR, Schellens JH, Nooijen WJ, Beijnen JH. Cremophor EL causes (pseudo-) non-linear pharmacokinetics of paclitaxel in patients. Br J Cancer. 1999;81(2): 330-335.

8. Sparreboom A, van Zuylen L, Brouwer E, et al. Cremophor EL-mediated alteration of paclitaxel distribution in human blood: clinical pharmacokinetic implications. Cancer Res. 1999;59(7):1454-1457.

9. Desai N, Trieu V, Yao Z, et al. Increased antitumor activity, intratumor paclitaxel concentrations, and endothelial cell transport of cremophorfree, albumin-bound paclitaxel, ABI-007, compared with cremophorbased paclitaxel. Clin Cancer Res. 2006;12(4):1317-1324.

10. Desai N, Trieu V, Damascelli B, Soon-Shiong P. SPARC Expression Correlates with Tumor Response to Albumin-Bound Paclitaxel in Head and Neck Cancer Patients. Transl Oncol. 2009;2(2):59-64.

11. Maeda H, Wu J, Sawa T, Matsumura Y, Hori K. Tumor vascular permeability and the EPR effect in macromolecular therapeutics: a review. J Control Release. 2000;65(1-2):271-284. 
12. Yardley DA. nab-Paclitaxel mechanisms of action and delivery. J Control Release. 2013;170(3):365-372.

13. Chen N, Li Y, Ye Y, Palmisano M, Chopra R, Zhou S. Pharmacokinetics and pharmacodynamics of nab-paclitaxel in patients with solid tumors: disposition kinetics and pharmacology distinct from solvent-based paclitaxel. J Clin Pharmacol. 2014;54(10):1097-1107.

14. Li Y, Chen N, Palmisano M, Zhou S. Pharmacologic sensitivity of paclitaxel to its delivery vehicles drives distinct clinical outcomes of paclitaxel formulations. Mol Pharm. 2015;12(4):1308-1317.

15. Gradishar WJ, Tjulandin S, Davidson N, et al. Phase III trial of nanoparticle albumin-bound paclitaxel compared with polyethylated castor oil-based paclitaxel in women with breast cancer. J Clin Oncol. 2005;23(31):7794-7803

16. Socinski MA, Bondarenko I, Karaseva NA, et al. Weekly nab-paclitaxel in combination with carboplatin versus solvent-based paclitaxel plus carboplatin as first-line therapy in patients with advanced non-smallcell lung cancer: final results of a phase III trial. J Clin Oncol. 2012; 30(17):2055-2062

17. Hirsh V, Okamoto I, Hon JK, et al. Patient-reported neuropathy and taxane-associated symptoms in a phase 3 trial of nab-paclitaxel plus carboplatin versus solvent-based paclitaxel plus carboplatin for advanced non-small-cell lung cancer. $J$ Thorac Oncol. 2014;9(1):83-90.

18. Ibrahim NK, Desai N, Legha S, et al. Phase I and pharmacokinetic study of ABI-007, a Cremophor-free, protein-stabilized, nanoparticle formulation of paclitaxel. Clin Cancer Res. 2002;8(5):1038-1044.

19. Nabholtz JM, Gelmon K, Bontenbal M, et al. Multicenter, randomized comparative study of two doses of paclitaxel in patients with metastatic breast cancer. J Clin Oncol. 1996;14(6):1858-1867.

20. Nyman DW, Campbell KJ, Hersh E, et al. Phase I and pharmacokinetics trial of ABI-007, a novel nanoparticle formulation of paclitaxel in patients with advanced nonhematologic malignancies. J Clin Oncol. 2005; 23(31):7785-7793.

21. Ibrahim NK, Samuels B, Page R, et al. Multicenter phase II trial of ABI-007, an albumin-bound paclitaxel, in women with metastatic breast cancer. J Clin Oncol. 2005;23(25):6019-6026.

22. Socinski MA, Manikhas GM, Stroyakovsky DL, et al. A dose finding study of weekly and every-3-week nab-Paclitaxel followed by carboplatin as first-line therapy in patients with advanced non-small cell lung cancer. J Thorac Oncol. 2010;5(6):852-861.

23. Socinski MA, Langer CJ, Okamoto I, et al. Safety and efficacy of weekly $\mathrm{nab}^{\circledR}$-paclitaxel in combination with carboplatin as first-line therapy in elderly patients with advanced non-small-cell lung cancer. Ann Oncol. 2013;24(2):314-321

24. Socinski MA, Okamoto I, Hon JK, et al. Safety and efficacy analysis by histology of weekly nab-paclitaxel in combination with carboplatin as first-line therapy in patients with advanced non-small-cell lung cancer. Ann Oncol. 2013;24(9):2390-2396.

25. Burris HA 3rd, Moore MJ, Andersen J, et al. Improvements in survival and clinical benefit with gemcitabine as first-line therapy for patients with advanced pancreas cancer: a randomized trial. J Clin Oncol. 1997; 15(6):2403-2413.

26. Tarceva ${ }^{\circledR}$ (erlotinib) tablets, for oral use [package insert]. South San Francisco, CA: Genentech USA, Inc; 2014.

27. Moore MJ, Goldstein D, Hamm J, et al; National Cancer Institute of Canada Clinical Trials Group. Erlotinib plus gemcitabine compared with gemcitabine alone in patients with advanced pancreatic cancer: a phase III trial of the National Cancer Institute of Canada Clinical Trials Group. J Clin Oncol. 2007;25(15):1960-1966.

28. Berlin JD, Catalano P, Thomas JP, Kugler JW, Haller DG, Benson AB 3rd. Phase III study of gemcitabine in combination with fluorouracil versus gemcitabine alone in patients with advanced pancreatic carcinoma: Eastern Cooperative Oncology Group Trial E2297. J Clin Oncol. 2002; 20(15):3270-3275.

29. Abou-Alfa GK, Letourneau R, Harker G, et al. Randomized phase III study of exatecan and gemcitabine compared with gemcitabine alone in untreated advanced pancreatic cancer. J Clin Oncol. 2006; 24(27):4441-4447.
30. Herrmann R, Bodoky G, Ruhstaller T, et al; Swiss Group for Clinical Cancer Research; Central European Cooperative Oncology Group. Gemcitabine plus capecitabine compared with gemcitabine alone in advanced pancreatic cancer: a randomized, multicenter, phase III trial of the Swiss Group for Clinical Cancer Research and the Central European Cooperative Oncology Group. J Clin Oncol. 2007; 25(16):2212-2217.

31. Louvet C, Labianca R, Hammel P, et al; GERCOR; GISCAD. Gemcitabine in combination with oxaliplatin compared with gemcitabine alone in locally advanced or metastatic pancreatic cancer: results of a GERCOR and GISCAD phase III trial. J Clin Oncol. 2005; 23(15):3509-3516.

32. Rocha Lima CM, Green MR, Rotche R, et al. Irinotecan plus gemcitabine results in no survival advantage compared with gemcitabine monotherapy in patients with locally advanced or metastatic pancreatic cancer despite increased tumor response rate. J Clin Oncol. 2004; 22(18):3776-3783.

33. Von Hoff DD, Ramanathan RK, Borad MJ, et al. Gemcitabine plus nab-paclitaxel is an active regimen in patients with advanced pancreatic cancer: a phase I/II trial. J Clin Oncol. 2011;29(34):4548-4554.

34. Frese KK, Neesse A, Cook N, et al. nab-Paclitaxel potentiates gemcitabine activity by reducing cytidine deaminase levels in a mouse model of pancreatic cancer. Cancer Discov. 2012;2(3):260-269.

35. Von Hoff DD, Ervin T, Arena FP, et al. Increased survival in pancreatic cancer with nab-paclitaxel plus gemcitabine. $N$ Engl J Med. 2013; 369(18):1691-1703.

36. Gradishar WJ, Krasnojon D, Cheporov S, et al. Phase II trial of nabpaclitaxel compared with docetaxel as first-line chemotherapy in patients with metastatic breast cancer: final analysis of overall survival. Clin Breast Cancer. 2012;12(5):313-321.

37. Hidalgo M, Plaza C, Illei PB, et al. SPARC analysis in the phase III MPACT trial of nab-paclitaxel plus gemcitabine vs gemcitabine alone for patients with metastatic pancreatic cancer. Ann Oncol. 2015; 25(Suppl 2):ii106.

38. Gradishar WJ, Krasnojon D, Cheporov S, et al. Significantly longer progression-free survival with nab-paclitaxel compared with docetaxel as first-line therapy for metastatic breast cancer. J Clin Oncol. 2009;27(22):3611-3619.

39. O'Shaughnessy J, Gradishar WJ, Bhar P, Iglesias J. Nab-paclitaxel for first-line treatment of patients with metastatic breast cancer and poor prognostic factors: a retrospective analysis. Breast Cancer Res Treat. 2013;138(3):829-837.

40. Lobo C, Lopes G, Baez O, et al. Final results of a phase II study of nab-paclitaxel, bevacizumab, and gemcitabine as first-line therapy for patients with HER2-negative metastatic breast cancer. Breast Cancer Res Treat. 2010;123(2):427-435.

41. Hamilton E, Kimmick G, Hopkins J, et al. Nab-paclitaxel/bevacizumab/ carboplatin chemotherapy in first-line triple negative metastatic breast cancer. Clin Breast Cancer. 2013;13(6):416-420.

42. Rugo HS, Barry WT, Moreno-Aspitia A, et al. CALGB 40502/ NCCTG N063H: randomized phase III trial of weekly paclitaxel compared to weekly nanoparticle albumin bound nab-paclitaxel or ixabepilone $+/-$ bevacizumab as first-line therapy for locally recurrent or metastatic breast cancer. J Clin Oncol. 2012;30(Suppl): Abstract CRA1002.

43. Untch M, Jackisch C, Schneeweiss A, et al. A randomized phase III trial comparing nanoparticle-based ( $n a b$ ) paclitaxel with solvent-based paclitaxel as part of neoadjuvant chemotherapy for patients with early breast cancer GBG 69 (GeparSepto). Abstract S2-07. Presented at: 2014 San Antonio Breast Cancer Symposium, December 9-13, 2014, San Antonio, Texas. Available from: http://www.sabcs.org/. Accessed May 7, 2015.

44. Patt D, Liang C, Li L, et al. Safety and efficacy of nab-paclitaxel in patients with metastatic breast cancer: real-world results from a US health insurance database. J Clin Oncol. 2014;5s(Suppl): Abstract 1075. Available from: http://sabcs.org/programschedule/PosterSessions. asp?SessionGroupID=154. Accessed July 9, 2015. 
45. NCCN Clinical Practice Guidelines in Oncology. Breast Cancer. V2. 2015. Available from: http://www.nccn.org/professionals/ physician_gls/pdf/breast.pdf. Accessed March 16, 2015. Available from: www.nccn.org/professionals/physician_gls/pdf/breast.pdf. Accessed July 9, 2015.

46. Liedtke C, Mazouni C, Hess KR, et al. Response to neoadjuvant therapy and long-term survival in patients with triple-negative breast cancer. J Clin Oncol. 2008;26(8):1275-1281.

47. Roy V, LaPlant BR, Gross GG, Bane CL, Palmieri FM; North Central Cancer Treatment Group. Phase II trial of weekly nab (nanoparticle albumin-bound)-paclitaxel (nab-paclitaxel) (Abraxane ${ }^{\circledR}$ ) in combination with gemcitabine in patients with metastatic breast cancer (N0531). Ann Oncol. 2009;20(3):449-453.

48. Celgene Corporation. Evaluate risk/benefit of nab paclitaxel in combination with gemcitabine and carboplatin compared to gemcitabine and carboplatin in triple negative metastatic breast cancer (or metastatic triple negative breast cancer) (tnAcity). In: ClinicalTrials.gov [website on the Internet]. Bethseda, MD: US National Library of Medicine; 2013 [updated June 12, 2015]. Available from: https://clinicaltrials. gov/show/NCT01881230. NLM identifier: NCT01881230. Accessed June 22, 2015.

49. Hofmann D, Nitz U, Gluz O, et al. WSG ADAPT - adjuvant dynamic marker-adjusted personalized therapy trial optimizing risk assessment and therapy response prediction in early breast cancer: study protocol for a prospective, multi-center, controlled, non-blinded, randomized, investigator initiated phase II/III trial. Trials. 2013;14:261.

50. West German Study Group. Adjuvant Dynamic Marker-Adjusted Personalized Therapy Trial Optimizing Risk Assessment and Therapy Response Prediction in Early Breast Cancer (ADAPT). In: ClinicalTrials.gov [website on the Internet]. Bethseda, MD: US National Library of Medicine; 2013 [updated May 18, 2015]. Available from: https://clinicaltrials.gov/ct2/show/NCT01781338. NLM identifier: NCT01781338. Accessed June 22, 2015.

51. Fondazione Michelangelo. Neoadjuvant chemotherapy with nabpaclitaxel in women with HER2-negative high-risk breast cancer (ETNA). In: ClinicalTrials.gov [website on the Internet]. Bethseda, MD: US National Library of Medicine; 2013 [updated May 25, 2015]. Available from: https://clinicaltrials.gov/ct2/show/NCT01822314. NLM identifier: NCT01822314. Accessed June 22, 2015.

52. German Breast Group. Study of nab-paclitaxel in high risk early breast cancer (GAIN-2). In: ClinicalTrials.gov [website on the Internet]. Bethseda, MD: US National Library of Medicine; 2012 [updated November 26, 2015]. Available from: https://clinicaltrials.gov/ct2/show/NCT01690702. NLM identifier: NCT01690702. Accessed May 4, 2015.

53. Hoffmann-La Roche. A study of Perjeta (pertuzumab) and Herceptin (trastuzumab) treatment in combination with a taxane in patients with advanced HER2-positive breast cancer. In: ClinicalTrials.gov [website on the Internet]. Bethseda, MD: US National Library of Medicine; 2013 [updated June 1, 2015]. Available from: https://clinicaltrials.gov/ ct2/show/NCT02019277. NLM identifier: NCT02019277. Accessed June 22, 2015.

54. Hoffmann-La Roche. A study of pertuzumab in combination with Herceptin (trastuzumab) and a taxane in first-line treatment in patients with HER2-positive advanced breast cancer (PERUSE). In: ClinicalTrials.gov [website on the Internet]. Bethseda, MD: US National Library of Medicine; 2012 [updated June 1, 2015]. Available from: https://clinicaltrials.gov/ct2/show/NCT01572038. NLM identifier: NCT01572038. Accessed June 22, 2015.

55. Howlader N, Noone AM, Krapcho M, et al, editors. SEER Cancer Statistics Review, 1975-2010 [web page on the Internet]. Bethesda, MD: National Cancer Institute; 2013 [updated June 14, 2013]. Available from: http:// seer.cancer.gov/archive/csr/1975_2010/. Accessed June 22, 2015.

56. Langer CJ, Manola J, Bernardo P, et al. Cisplatin-based therapy for elderly patients with advanced non-small-cell lung cancer: implications of Eastern Cooperative Oncology Group 5592, a randomized trial. J Natl Cancer Inst. 2002;94(3):173-181.
57. Langer CJ, Vangel M, Schiller J, et al. Age-specific subanalysis of ECOG 1594: fit elderly patients (70-80 yrs) with NSCLC do as well as younger pts $(<70)$. Proc Am Soc Clin Oncol. 2003;22:639.

58. Lilenbaum RC, Herndon JE II, List MA, et al. Single-agent versus combination chemotherapy in advanced non-small-cell lung cancer: the cancer and leukemia group B (study 9730). J Clin Oncol. 2005;23(1):190-196.

59. Blanchard EM, Moon J, Hesketh PJ, et al. Comparison of platinumbased chemotherapy in patients older and younger than 70 years: an analysis of Southwest Oncology Group Trials 9308 and 9509. J Thorac Oncol. 2011;6(1):115-120.

60. Ramalingam SS, Dahlberg SE, Langer CJ, et al; Eastern Cooperative Oncology Group. Outcomes for elderly, advanced-stage non small-cell lung cancer patients treated with bevacizumab in combination with carboplatin and paclitaxel: analysis of Eastern Cooperative Oncology Group Trial 4599. J Clin Oncol. 2008;26(1):60-65.

61. Sehl M, Sawhney R, Naeim A. Physiologic aspects of aging: impact on cancer management and decision making, part II. Cancer J. 2005; 11(6):461-473

62. Aymanns C, Keller F, Maus S, Hartmann B, Czock D. Review on pharmacokinetics and pharmacodynamics and the aging kidney. Clin J Am Soc Nephrol. 2010;5(2):314-327.

63. Celgene Corporation. Safety and efficacy study of Abraxane in combination with carboplatin to treat advanced NSCL cancer in the elderly (ABOUND 70+). Available from: https://www.clinicaltrials.gov/ ct2/show/NCT02151149. NLM identifier: NCT02151149. Accessed May 4, 2015.

64. Cetin K, Ettinger DS, Hei YJ, O'Malley CD. Survival by histologic subtype in stage IV nonsmall cell lung cancer based on data from the Surveillance, Epidemiology and End Results Program. Clin Epidemiol. 2011;3:139-148.

65. NCCN Clinical Practice Guidelines in Oncology. Non-Small Cell Lung Cancer. V5. 2015. Available from: http://www.ncen.org/professionals/physician_gls/pdf/nscl.pdf. Accessed March 16, 2015. Available from: http://www.nccn.org/professionals/physician_gls/pdf/nscl.pdf. Accessed July 9, 2015.

66. Celgene Corporation. Safety and efficacy study of Abraxane as maintenance treatment after Abraxane plus carboplatin in 1st line stage IIIB /IV squamous cell non-small cell lung cancer (aboundsqm). Available from: https://clinicaltrials.gov/ct2/show/NCT02027428. NLM identifier: NCT02027428. Accessed May 4, 2015.

67. NCCN Clinical Practice Guidelines in Oncology. Pancreatic Adenocarcinoma. V2. 2015. Available from: http://www.nccn.org/ professionals/physician_gls/pdf/pancreatic.pdf. Accessed March 16, 2015. Available from: http://www.nccn.org/professionals/physician_gls/ pdf/pancreatic.pdf. Accessed July 9, 2015.

68. Oettle H, Neuhaus P, Hochhaus A, et al. Adjuvant chemotherapy with gemcitabine and long-term outcomes among patients with resected pancreatic cancer: the CONKO-001 randomized trial. JAMA. 2013;310(14):1473-1481

69. Ueno H, Kosuge T, Matsuyama Y, et al. A randomised phase III trial comparing gemcitabine with surgery-only in patients with resected pancreatic cancer: Japanese Study Group of Adjuvant Therapy for Pancreatic Cancer. Br J Cancer. 2009;101(6):908-915.

70. Celgene Corporation. Nab-paclitaxel and gemcitabine vs gemcitabine alone as adjuvant therapy for patients with resected pancreatic cancer (the "Apact" study) (apact). In: ClinicalTrials.gov [website on the Internet]. Bethseda, MD: US National Library of Medicine; 2013 [updated June 5, 2015]. Available from: https://clinicaltrials.gov/ct2/ show/NCT01964430. NLM identifier: NCT01964430. Accessed June 22, 2015.

71. NewLink Genetics Corporation. Immunotherapy study in borderline resectable or locally advanced unresectable pancreatic cancer (PILLAR). In: ClinicalTrials.gov [website on the Internet]. Bethseda, MD: US National Library of Medicine; 2013 [updated March 26, 2015]. Available from: https://clinicaltrials.gov/ct2/show/NCT01836432. NLM identifier: NCT01836432. Accessed May 4, 2015. 
72. NCCN Clinical Practice Guidelines in Oncology. Melanoma. V2. 2015. Available from: http://www.nccn.org/professionals/physician_gls/pdf/ melanoma.pdf. Accessed March 16, 2015.

73. NCCN Clinical Practice Guidelines in Oncology. Ovarian Cancer Including Fallopian Tube Cancer and Primary Peritoneal Cancer. V1. 2015. Available from: http://www.nccn.org/professionals/ physician_gls/pdf/ovarian.pdf. Accessed March 16, 2015.

74. Hersh EM, O’Day SJ, Ribas A, et al. A phase 2 clinical trial of nabpaclitaxel in previously treated and chemotherapy-naive patients with metastatic melanoma. Cancer. 2010;116(1):155-163.

75. Kottschade LA, Suman VJ, Amatruda T III, et al. A phase II trial of nab-paclitaxel (ABI-007) and carboplatin in patients with unresectable stage IV melanoma: a North Central Cancer Treatment Group Study, N057E(1). Cancer. 2011;117(8):1704-1710.

76. Hersh E, Del Vecchio M, Brown MP, et al. Final overall survival from a phase III trial of nab-paclitaxel vs dacarbazine in chemotherapy-naive patients with metastatic melanoma. J Clin Oncol. 2014;5s(Suppl): Abstract 9045.

77. Academic and Community Cancer Research United. Paclitaxel albuminstabilized nanoparticle formulation and bevacizumab or ipilimumab as first-line therapy in treating patients with stage IV melanoma that cannot be removed by surgery. In: ClinicalTrials.gov [website on the Internet]. Bethseda, MD: US National Library of Medicine; 2014 [updated June 15, 2015]. Available from: https://clinicaltrials.gov/ct2/show/ NCT02158520. NLM identifier: NCT02158520. Accessed June 22, 2015.

78. MD Anderson Cancer Center. Phase II study of Abraxane plus ipilimumab in patients with metastatic melanoma. In: ClinicalTrials. gov [website on the Internet]. Bethseda, MD: US National Library of Medicine; 2013 [updated December 18, 2014]. Available from: https://clinicaltrials.gov/ct2/show/NCT01827111. NLM identifier: NCT01827111. Accessed May 4, 2015.

79. Teneriello MG, Tseng PC, Crozier M, et al. Phase II evaluation of nanoparticle albumin-bound paclitaxel in platinum-sensitive patients with recurrent ovarian, peritoneal, or fallopian tube cancer. J Clin Oncol. 2009;27(9):1426-1431.
80. Luvero D, Milani A, Ledermann JA. Treatment options in recurrent ovarian cancer: latest evidence and clinical potential. Ther Adv Med Oncol. 2014;6(5):229-239.

81. Coleman RL, Brady WE, McMeekin DS, et al. A phase II evaluation of nanoparticle, albumin-bound (nab) paclitaxel in the treatment of recurrent or persistent platinum-resistant ovarian, fallopian tube, or primary peritoneal cancer: a Gynecologic Oncology Group study. Gynecol Oncol. 2011;122(1):111-115.

82. Tillmanns TD, Lowe MP, Walker MS, Stepanski EJ, Schwartzberg LS. Phase II clinical trial of bevacizumab with albumin-bound paclitaxel in patients with recurrent, platinum-resistant primary epithelial ovarian or primary peritoneal carcinoma. Gynecol Oncol. 2013;128(2):221-228.

83. UNC Lineberger Comprehensive Cancer Center. Induction chemotherapy for locally advanced squamous cell carcinoma of the head and neck. In: ClinicalTrials.gov [website on the Internet]. Bethseda, MD: US National Library of Medicine; 2011 [updated February 28, 2014]. Available from: https://clinicaltrials.gov/ct2/show/NCT01412229. NLM identifier: NCT01412229. Accessed May 4, 2015.

84. Chinese Academy of Medical Sciences. First line chemotherapy for advanced cancer (GC-A-003). In: ClinicalTrials.gov [website on the Internet]. Bethseda, MD: US National Library of Medicine; 2013. Available from: https://clinicaltrials.gov/ct2/show/NCT01980810. NLM identifier: NCT01980810. Accessed May 4, 2015.

85. MD Anderson Cancer Center. Abraxane in CIMP-high colorectal and small bowel adenocarcinomas. In: ClinicalTrials.gov [website on the Internet]. Bethseda, MD: US National Library of Medicine; 2012 [updated February 9, 2015]. Available from: https://clinicaltrials.gov/ ct2/show/NCT01730586. NLM identifier: NCT01730586. Accessed May 4, 2015.

86. Ma P, Mumper RJ. Paclitaxel Nano-Delivery Systems: A Comprehensive Review. J Nanomed Nanotechnol. 2013;4(2):1000164.

87. Celgene Europe Limited. Abraxane [summary of product characteristics]. London: European Medicines Agency; nd. Available from: http:/www.ema. europa.eu/docs/en_GB/document_library/EPAR_-_Product_Information/ human/000778/WC500020435.pdf. Accessed June 4, 2015.

\section{Publish your work in this journal}

Drug Design, Development and Therapy is an international, peerreviewed open-access journal that spans the spectrum of drug design and development through to clinical applications. Clinical outcomes, patient safety, and programs for the development and effective, safe, and sustained use of medicines are a feature of the journal, which

\section{Dovepress}

has also been accepted for indexing on PubMed Central. The manuscript management system is completely online and includes a very quick and fair peer-review system, which is all easy to use. Visit http://www.dovepress.com/testimonials.php to read real quotes from published authors. 